\title{
How institutional logics hamper innovation: The case of animal testing
}

\author{
Marlous Kooijman ${ }^{\text {a }}$, Marko P. Hekkert ${ }^{\mathrm{a}, *}$, Peter J.K. van Meer ${ }^{\mathrm{b}}$, Ellen H.M. Moors ${ }^{\text {a }}$, Huub Schellekens ${ }^{\mathrm{b}}$ \\ a Innovation Studies, Copernicus Institute, Utrecht University, Heidelberglaan 2, 3584 CS Utrecht, The Netherlands \\ ${ }^{\mathrm{b}}$ Utrecht Institute for Pharmaceutical Sciences, Utrecht University, Universiteitsweg 99, 3584 CG Utrecht, The Netherlands
}

\section{A R T I C L E I N F O}

Article history:

Received 21 March 2014

Received in revised form 25 November 2016

Accepted 5 February 2017

Available online 16 February 2017

\section{Keywords:}

Institutional logics

Technological Innovation System

Animal studies

Erythropoietin

\begin{abstract}
A B S T R A C T
For radical innovation to become successful the substitution of established practices are essential. Nevertheless, in the innovation literature novelty is often at the center and only little attention is paid to the influence of established technologies and underlying routines. This paper aims to contribute to this gap by increasing the understanding about the effect of persistence of established practices on the innovation process. We do this by using a framework that combines the Technological Innovation System approach with an analysis of the institutional logics reinforcing the established practice. The studied case concerns the innovation process to animal-free medicine development. Despite the fact that the substitution of animal tests is called for since the 1980s and animalfree methods are available, animal tests are still being used in medicine development. This study shows that adding institutional logics to the innovation systems analysis creates a much better understanding of the speed and direction of radical innovation.
\end{abstract}

(C) 2017 Published by Elsevier Inc.

\section{Introduction}

Radical innovations are necessary to tackle the grand societal challenges society is currently facing. The transformation of socio-technical systems, including technical, organizational, economic, institutional, social-cultural and political changes, due to the introduction and diffusion of radical innovation are referred to as sociotechnical transitions (Van den Bergh et al., 2011). The research field of transition studies tries to understand the mechanisms that underlie these complex change processes (Markard et al., 2012). This resulted in frameworks to study the dynamics of transition processes as the Multi-Level Perspective (MLP) and the Technological Innovation System (TIS) approach. Both frameworks recognize that new technologies are key to realize societal transitions and that transitions do not easily occur because new technologies are often poorly aligned with established practices (Kemp et al., 1998; Geels, 2002; Hekkert et al., 2007). Nevertheless, novelty is at the center of attention in most transition studies. For example, the TIS approach focuses on emerging technologies and the development of the innovation system supporting the emerging technology (Negro et al., 2008; Suurs and Hekkert, 2009; Van Alphen et al., 2010). This approach regards the success of innovations mainly as a consequence of the performance of the innovation system and the capability of innovation system actors to impact dominant socio-institutional structures. It does not conceptualize explicitly the broader context outside the TIS such as established

\footnotetext{
* Corresponding author.

E-mail addresses: Marlous.Kooijman@gmail.com (M. Kooijman), M.P.Hekkert@uu.nl (M.P. Hekkert), P.J.K.vanMeer@uu.nl (P.J.K. van Meer), E.H.M.Moors@uu.nl (E.H.M. Moors), h.schellekens@uu.nl (H. Schellekens).
}

practices (Markard and Truffer, 2008). The importance of a better understanding of the TIS context is stressed in a recent article by Bergek et al. (2015). Contrary to the TIS framework, the MLP framework does take the established practice and underlying rules into account. For this, the regime concept is used. The regime, however, is often analyzed only as a barrier to be overcome or as creating windows of opportunity and not as a dynamic context continuously influencing the innovation process (Geels, 2005; Elzen et al., 2011; Yuan et al., 2012).

In the transition literature there is strong recognition that the success of emerging technologies depends as much on the development of the emerging technology as on changing technical regimes (Kemp et al., 1998; Turnheim and Geels, 2012). Nevertheless, the transition literature pays little attention to understanding how the persistence of established practices and underlying rules can impact the creation of novelty. In MLP terms: far less notice is taken of processes that stabilize the technical regime (Turnheim and Geels, 2012). This paper contributes to this gap by focusing on how established practices persist and influence the innovation process of emerging technologies.

This paper focuses on the persistency of established technologies by taking an institutional theory perspective. This is in line with Fuenfschilling and Truffer (2014) who operationalized socio-technical regimes by making use of the institutional logics theory. The term institution refers to rules. Not just rules in the form of a set of commands and requirements, but also rules in the sense of roles and practices that are being established and that are not easily dissolved (Kemp et al., 1998). Following institutional theory stability and change can be understood in terms of institutional logics. Institutional logics refer to 'the belief systems and related practices that predominate in an organizational field' (Scott, 2001, p 139). They provide the organizing principles of a field 
(Friedland and Alford, 1991). A poor fit of emerging technologies with the prevailing institutional logic hampers successful diffusion, because it creates economic, technological, cognitive and social barriers for new technologies (Kemp et al., 1998). Change in the institutional logic is then essential for innovation to become successful (Reay and Hinings, 2009). The reason for deploying the TIS approach in this study is that it is praised for its powerful analysis of the conditions that enable and hamper emerging technological innovation processes (Markard and Truffer, 2008). The aim of this paper is twofold. First, we aim to increase understanding about how established practices persist, often labeled as lock-in, while pressured by novelty and how they influence the innovation process of emerging technologies. We already know that several types of feedback loops reinforce lock-in processes as explained by Unruh (2000) who proposed the concept of Techno-Institutional Complex (TIC). While Unruh (2000) highlights the interaction between technological systems and institutional systems, he underconceptualized the institutional dimension in lock-in processes. In this study we aim to enrich insight in the institutional dimension of lockin. Second, we aim to conceptually improve the TIS perspective by combining the TIS approach to analyze the innovation process of emerging technologies with an analysis of the institutional logic related to established practices. Third, applying a framework that stems from institutional theory may be worthwhile for the broader field of innovation studies. The evolutionary perspective on innovation highlights the importance of institutions through the use of concepts like technological paradigms and technological trajectories (Dosi, 1982). Using institutional theory as we propose in this paper may create a more detailed insight in what institutional mechanisms create technological paradigms and trajectories.

We selected the change process towards animal-free testing medicine development as empirical field. Despite the fact that the replacement of animal testing is called for by a range of actors since the 1980s, animal tests are still deeply embedded in medicine development. Therefore, this empirical field is very useful to increase our understanding about why established practices persist when confronted with emerging technologies. Furthermore, the desired change process towards animal-free testing shares characteristics with socio-technical transitions. Turnheim and Geels (2012), for example, describe low-carbon transitions as purposive transitions, which are deliberately pursued from the start to solve an explicit set of societal problems. Because private actors have limited incentives to address societal problems (because of market failures and free-rider problems), it is likely that social movements, public opinion, and policy makers play important roles in purposive transitions (Turnheim and Geels, 2012). Just like low-carbon transitions, the change process to animal-free methods in medicine development can be regarded as a purposive change process to solve the problem of the undesired use of animal tests in which private actors have limited incentives.

To explore the persistence of the institutional logic reinforcing established animal testing practices and the effect of this persistence on emerging animal-free methods we study one particular case; the erythropoietin (EPO) potency test in mice. $\mathrm{EPO}^{1}$ is a biotechnology-derived medicine developed to treat patients with anemia. This case is of particular interest because EPO received market authorization at the end of the 1980s just after European legislation was implemented that discouraged animal testing and promoted the use of animal-free methods. Despite the public resistance to the use of animal tests, and the availability of animal-free methods, European quality control regulation still requires that the potency of every batch of EPO is assessed in mice. We will show that the institutional logics framework explains why the animal test persisted and how the persistency of this

${ }^{1}$ EPO is a natural occurring hormone EPO controls the red blood cell production in humans. A lack of this hormone causes anemia. EPO is also known as a forbidden performance-enhancing drug in professional sports. established practice hampered the development and use of innovative (animal-free) methods.

\section{Theoretical framework}

In the mid-1980s innovation system approaches were developed in reaction to perceived inadequacies to explain innovation and change processes by neoclassical economics (Sharif, 2006). The Technological Innovation System (TIS) approach is one of the innovation system approaches and is used to conceptualize and analyze the complex process of the development, diffusion and use of new technologies (Bergek et al., 2008; Hekkert and Negro, 2009). The basic assumption of the TIS approach is that innovations do not develop in isolation, but that a sociotechnical system, including policy and perceived legitimacy, enables the development, diffusion and use of technologies. An innovation system consists of actors that contribute to the innovation process in a wide variety of ways, for instance through knowledge development, supply of financial resources, standardization, and use of the innovation. These actors are constrained and enabled in their actions by the structure of the innovation system that consists of network characteristics, technological artifacts and institutional settings.

The functional analysis of the TIS focuses on the key processes that take place in the innovation system (see Table 1). These key processes are necessary to provide the necessary circumstances for actors to innovate. When an innovation system is in an emerging stage of development, these key processes contribute to the build-up of the innovation system's structure. When this structure is in place, innovation becomes easier. Important features of systems are the strong complementarities that commonly exist between the components of and processes in a system. If, in a system, one critical component or process is lacking, this may block or slow down the performance of the entire system (Hekkert et al., 2007). Thus, when one or more of these key processes do not take place sufficiently, innovation can be hampered (Jacobsson and Bergek, 2011).

The powerful analysis of the performance of emerging technological fields is the key contribution of the TIS approach to innovation studies (Markard and Truffer, 2008). The main critique on this approach is that it regards the success of innovations mainly as a consequence of the performance of the TIS and does not systematically take into account external influences such as established practices and its underlying rules (Markard and Truffer, 2008). In a recent contribution by Bergek et al. (2015) the context of a TIS is conceptualized by distinguishing several context systems, like other TIS, sectors, policy, and geographical systems. While this is very useful, the deep underlying structures that strongly influence agentic behavior in these different context systems is not conceptualized. We take up the challenge of repairing this weakness by making use of the rich body of literature on institutional theory to conceptualize the context of established practices to enrich the TIS approach.

Institutional theory studies the deeper and more resilient aspects of social structures (Scott, 2008). Scott defines institutions as follows: "Institutions are comprised of regulative, normative and cultural-cognitive elements that, together with associated activities and resources provide stability and meaning to social life" (Scott, 2008, p 48). Thus, institutions are the taken-for-granted rules (e.g. regulations, user practices, symbolic meanings) that structure and stabilize the practices of daily life (Seo and Creed, 2002; Kalantaridis and Fletcher, 2012). Institutions have distinctive properties. They are relatively resistant to change and they tend to be maintained and reproduced across generations (Scott, 2008). Institutions control and constrain behavior because they impose restrictions by defining legal, moral and cultural boundaries, setting off legitimate from illegitimate activities (Scott, 2008; Kalantaridis and Fletcher, 2012; Thornton et al., 2012). However, institutions also support and empower activities and actors (Lawrence and Suddaby, 2006; Thornton et al., 2012). Institutional scholars study how 
Table 1

Key activities of the innovation system (based on Hekkert et al., 2007; Negro et al., 2007).

\begin{tabular}{ll}
\hline Key processes & Indicators \\
\hline 1 Entrepreneurial activity & \\
Entrepreneurs are either new entrants & Experiments with the innovative \\
that see opportunities in new markets or & methods \\
incumbent companies who diversify their & \\
business to take advantage of new & \\
developments. They are essential for a \\
well-functioning innovation system \\
because they turn the potential of new \\
knowledge, networks and markets into \\
concrete actions to generate and take \\
advantage of business opportunities. By \\
entrepreneurial experimenting many \\
forms of learning takes place. More \\
knowledge is necessary to deal with the \\
uncertainties of emerging technologies. \\
The presence of active entrepreneurs is a \\
first and prime indication of the \\
performance of an innovation system. \\
When entrepreneurial activity lags \\
behind, causes may be found in the other \\
six functions. \\
Knowledge development \\
Knowledge development in fundamental Articles published about \\
for every innovation. Knowledge is the \\
basis of emerging technologies and is \\
important to reduce uncertainty and \\
improve the performance of new \\
products and processes. \\
Knowledge diffusion methods
\end{tabular}

3 Knowledge diffusion

Knowledge exchange is important in a strict R\&D setting, but especially in a heterogeneous context where R\&D meets government, competitors, and market. Policy decisions (standards, long term targets) should be consistent with the latest technological insights and, at the same time, R\&D agendas should be affected by changing norms and values.

4 Guidance of the search

Guidance of the search refers to those activities that can positively affect the visibility and clarity of specific wants among technology users. Since resources are almost always limited, it is important that, when various technological options exist, choices are made for further investments. Expectations are an important phenomenon when making these choices. Choices of actors are often initially driven by little more than a hunch.

5 Market creation Emerging technologies often have difficulties to compete with incumbent technologies, because they are still badly adapted to many of the uses to which they will be put. Incumbent enjoy increasing returns on investment whereas emerging technologies are expensive and often offer only very small advantages over previously existing techniques. To be able to compete with the incumbent technologies, creation of competitive advantages for emerging technologies is often necessary.

6 Resource mobilization

Resources, both financial and human capital, are necessary as a basic input for all activities within the innovation system.

7 Counteract resistance to change New technologies have to become part of Advocacy coalitions for innovative an incumbent regime, or have to overthrow it. Actors with vested interests will often oppose to this force of "creative
Table 1 (continued)

\begin{tabular}{ll}
\hline Key processes & Indicators \\
\hline destruction". Advocacy coalitions can put & \\
a new technology on the agenda & \\
(function 4), lobby for resources & \\
(function 6) and favorable tax regimes & (function 5), and by doing so create \\
legitimacy for a new technological \\
trajectory.
\end{tabular}

institutions are created, maintained, adapted and dismissed (Lawrence and Suddaby, 2006; Scott, 2008).

Scott (2008) distinguishes three types of institutional elements, which are referred to as regulative, normative and cultural-cognitive elements. First, the regulative elements are explicit, regulative rules, which constrain behavior and regulate interactions, for example, government regulations, which structure the economic process. Second, normative elements include values (the preferred or the desirable, together with the construction of standards to which existing structures or behaviors can be compared and assessed), norms (how things should be done), role expectations, duties, rights and responsibilities. Third, cultural-cognitive elements embrace the nature of reality and frames through which meaning or sense is made (Scott, 2008).

Thornton and Ocasio (2005, p 804) defined institutional logics as 'the socially constructed, historical patterns of material practices, assumptions, values, beliefs, and rules by which individuals produce and reproduce their material subsistence, organize time and space, and provide meaning to their social reality'. Institutional logics comprise of a set of institutions that are the basis of taken-for-granted rules guiding behavior of actors (Scott, 2008; Reay and Hinings, 2009). Scholars defined seven main societal institutional logics: the family, the community, the religion, the professions, the state, the corporation and the market (Friedland and Alford, 1991; Thornton et al., 2012). These societal institutional logics are reconfigured and translated in to institutional logics at multiple levels, such as the organizational and industrial level (Thornton and Ocasio, 2008). In this paper we study the institutional logic of medicine development at the industrial level.

Institutional logics are reinforced because they are taken for granted, normatively endorsed and backed up by authorized powers (Scott, 2008; Thornton et al., 2012). These logics are enacted through institutionalized practices that are reproduced within the field (Berman, 2012). The alignment of underlying assumptions, norms, beliefs and rules is important for the stability of the institutional logics because they enforce each other (Scott, 2008). When these elements are not well aligned, this provides conditions that are likely to give rise to alternative institutional logics and can result in institutional change (Hoffman, 1999; Caronna, 2004).

According to the literature, change in institutional logics is often driven by outsiders mobilizing resources and using social skills to promote change (Hardy and Maguire, 2008; Thornton and Ocasio, 2008). For example, Maguire and Hardy (2009) studied the outsider-driven abandonment of the practice of DDT use applying the institutional pillars of Scott (2001). They describe how the take-for-granted use of DDT was deinstitutionalized by undermining the three institutional pillars. Furthermore, change can also be induced by powerful insiders (Rao et al., 2012; Greenwood and Suddaby, 2006). Finally, social movements can play a role in triggering change as sources of new logics or acting to destabilize fields, such as the anti-genetics movement influencing the success of biotechnology products of pharmaceutical companies in Germany in 1980s (Weber et al., 2009).

Innovations strongly deviating from established institutional logic will have problems in breaking through. They will not be regarded as legitimate, will not be taken for granted and will not be supported by authorized powers. Actors that support the innovation therefore have to challenge the dominant institutional logic as it is essential for the success of innovations. This institutional change is often beyond the 
capacity of individual actors and therefore requires joint activities by a wide group of actors on the basis of mutual interests (Oliver, 1993; Wijen and Ansari, 2007). Collective inaction is often a problem in these change processes (Heckathorn, 1996). Collective inaction can be the result of the free-rider problem, lack of leadership and actor apathy because actors feel their contribution to the problem is insignificant (Wijen and Ansari, 2007). However, circumstances may change. Berman (2012, p 261) argues that "When one logic is dominant, innovations based on alternative logics may have trouble gaining the resources they need to become more broadly institutionalized. But if a changing environment starts systematically to favor practices based on an alternative logic, that logic can become stronger even in the absence of a coherent project to promote it".

In this paper we study the established practice of EPO potency testing in mice. To systematically identify the drug development logic that reinforces the practice of EPO potency testing in mice, we used the three institutional elements (regulative, normative and cultural-cognitive) of Scott (2008) as heuristic to explore the institutional logic.

\section{Method}

The institutional logic reinforcing the EPO potency testing practice in mice is analyzed in combination with the innovation process of innovative animal-free methods to increase understanding of how established practices persist when confronted with emerging technologies. To gain detailed insight we employed an explorative case study methodology (Yin, 2003). The studied case, the EPO potency practice, is an illustrative case of purposive change processes. We selected this particular case, because it is a relatively well-documented example where promising innovative methods did not manage to replace the problematized existing practice. Therefore, dynamics between the activities in the TIS and institutional logic are expected. In this way, this study in the field of animal-testing in medicine development could provide insights that are also valuable for transition studies in general.

A qualitative event history analysis was done to gain insight into the dynamics of the innovation process of animal-free methods that could replace the EPO potency test in mice and into the institutional logic reinforcing the EPO potency test in mice. In the event history analysis, the three institutional elements and the seven key processes of the TIS are operationalized (Tables 1 and 2).

Subsequently, events were identified and related to the institutional elements and key processes. An event can be defined as an instance of change with respect to the institutional elements and/or key processes of the TIS, which is the work of one or more actors and which carries some public importance with respect to the institutions and TIS under

Table 2

Institutional elements (based on Scott, 2008).

\begin{tabular}{|c|c|c|}
\hline & Elements & Indicators \\
\hline \multirow[t]{2}{*}{1} & Regulative & \\
\hline & $\begin{array}{l}\text { The regulative elements refer to explicit, formal } \\
\text { rules, which constrain behavior and regulate } \\
\text { interactions, for example, government regulations, } \\
\text { which structure the economic process. It is about } \\
\text { rewards and punishments backed up with } \\
\text { sanctions. }\end{array}$ & Rules, laws and sanctions \\
\hline \multirow[t]{2}{*}{2} & Normative & \\
\hline & $\begin{array}{l}\text { Normative elements are often highlighted by } \\
\text { traditional sociologists. These institutions confer } \\
\text { values, norms, role expectations, duties, rights and } \\
\text { responsibilities. }\end{array}$ & Norms and values \\
\hline \multirow[t]{2}{*}{3} & Cultural-cognitive & \\
\hline & $\begin{array}{l}\text { Cultural- cognitive elements constitute the nature } \\
\text { of reality and frames through which meaning or } \\
\text { sense is made. Symbols (words, concepts, myths, } \\
\text { signs, and gestures) have their effect by shaping } \\
\text { the meanings we attribute to objects and activities. }\end{array}$ & $\begin{array}{l}\text { Common beliefs and } \\
\text { shared logics of action }\end{array}$ \\
\hline
\end{tabular}

investigation. Examples of such events are scientific studies carried out, policy measures issued and norms that are changed.

Event history data are collected retrospectively making use of scientific literature, reports and websites (see Appendix). The delineation of the study is Europe, because EPO potency testing in mice is mandatory for European quality control. It is recognized that this innovation process of animal-free methods is influenced by activities worldwide. Some of these activities, such as the development of animal-free methods by researchers and manufacturers outside Europe, are also included in the analysis when they largely influenced the innovation process in Europe. The data is collected over a 40-year period from the early development of EPO in 1970 until 2010.

The identification of events was an inductive exercise for which the conceptual framework of key processes (Table 1 ) and institutional elements (Table 2) were used as a heuristic. With the definitions of the key processes and institutional elements in mind it was possible to interpret particular reports as events. The data has been triangulated using 9 semi-structured interviews with experts from industry and regulation (see Appendix). A storyline was constructed based on the events.

\section{The story of EPO potency testing}

The case study concerns the practice of EPO potency testing that, following the dominant logic of medicine development, had to be formalized in regulation in the 1990s. The narrative of EPO potency testing is elaborated in the following sections.

\subsection{The institutional logic of medicine development and the use of animal models}

In Europe, the first regulative element concerning the development of medicines was implemented in the 1960s with the adoption of Directive 65/65/EEC and it came into existence as a result of the Thalidomide tragedy $^{2}$ (Rägo and Santoso, 2008). This tragedy changed norms because medicines were no longer concerned ordinary consumers' products, as consumers were not in the position to make decisions about when, and how to use medicines. The Thalidomide tragedy made clear that even healthcare professionals did not have the capabilities to take informed decisions about all safety and quality aspects related to medicines. Governments became considered to be responsible for the protection of their citizens in fields where the citizens themselves are not able to do so (normative element). Governments therefore, required that all new medicines had to be approved by regulatory authorities based on the proven safety, efficacy and quality to gain market authorization (Rägo and Santoso, 2008).

Animals had been successfully used as a model for humans throughout the history in scientific research and education (Monamy, 2000). This success had created profound belief in animal tests and made the use of animal tests in medicine development to study the safety, efficacy and quality of medicines an obvious choice. Due to the deep belief in the value of animal models to predict effects in humans and the broad use of these models in scientific research (cultural-cognitive element), the animal experiments were implemented in regulative elements concerning the development of medicines even without thoroughly validating their ability to predict efficacy and safety in humans. Animal studies have been the golden standard in medicine development ever since (normative element). Even the scientific doubt on the predictive value of animal studies (e.g. Van Meer et al., 2012, 2013) did not influence the belief in and the position of animal studies as the golden standard in medicine development.

\footnotetext{
2 In the late 1950s, the sedative medicine, Thalidomide, was used to cure morning sickness amongst others for pregnant women. The medicine was withdrawn from the market in 1961 because it caused severe birth defects.
} 
Directive 2001/83/EC (regulative element) lays down that the European Directorate for the Quality of Medicines \& HealthCare (EDQM) is responsible for the quality control of medicines in the European Union (European Commission, 2001). The EDQM standards for quality control of medicines are prescribed in regulative elements; the monographs of the European Pharmacopoeia. The General Notices ${ }^{3}$ of the European Pharmacopoeia report that "statements in monographs constitute mandatory requirements" (EDQM, 2012, p 4453).

The duty of the EDQM is protecting public health by ensuring the quality of medicines (EDQM, n.d.). In order to fulfill this duty, the EDQM has to be intrinsically risk averse and conservative (normative elements). This norm to act precautious is a major barrier to change. An interviewee stated "the biggest problem is ... just intrinsic conservatism. Once you have something that works and you understand it, there is always resistance to change" (Industry2, 2011). As a result, an extensive validation procedure (see Fig. 1) and monograph revision process have to be followed to replace a test in the monographs of the European Pharmacopoeia (regulative elements) (Coune, 2007). Furthermore, innovative animal-free methods can only be implemented in the European Pharmacopoeia when the member states of the EDQM unanimously accept the new test (Regulator1, 2011).

The aim of the monographs of the European Pharmacopoeia is to assess the quality of medicines for humans (EDQM1, n.d.). When validating a new quality test, it would be most valuable to use the correlation between the effect of interest in humans and the results of the innovative test as validation endpoint. This is not the case. Instead, the correlation between the results of the animal-free method and the effect in animals is used (regulative element) (Industry1, 2011; NR L2, 2011; NR L3, 2011). This is problematic. The results of the animal tests are known to be variable and have limited sensitivity in many cases (Industry2, 2011). Thus, a non-ideal prediction model (animal test) for the effects on humans is used as a reference for the validation of animal-free methods. The rationale of using the animal data is that new methods are aimed at replacing that test (cultural-cognitive element).

Furthermore, regulators, manufacturers and scientists are still trained based on the notion that animal studies are the golden standard to assess the safety and quality of medicines for humans (cultural-cognitive element) (Industry2, 2011; Researcher3, 2011). The experience with animal studies and belief in the value of animal tests support the choice for this reference as quality issues in humans have been uncommon under the current regulation (cultural-cognitive element) (NR L1, 2011). Additionally, due to intrinsic conservatism (normative element) the EDQM requires that the results of innovative methods show high correlation with the results of established animal tests (regulative element). This is problematic when the animal test is variable and has limited sensitivity.

The institutional logic of medicine development has been in place since the 1960s. Since the start more and more well aligned institutional elements have been put in place. The most important institutional elements are the norm that medicine are not ordinary consumer products and the expectation that governments protect citizens (cultural cognitive). These elements made the implementation of regulative elements legitimate. Due to ruling cultural-cognitive elements animal studies became the golden standard in most regulative elements of the institutional logic of medicine development as it was the method or norm how medicines were studied.

\subsection{The emergence of animal-free methods for EPO potency testing}

Controversies have been surrounding animal experimentation throughout history (Ryder, 2000). The use of animal studies came under increasing pressure in the second half of the 20th century. Animal welfare organizations were set up and the predictive value of animal

\footnotetext{
${ }^{3}$ General Notices 10000 E of the European Pharmacopoeia apply to all the monographs
}

tests in drug development came under extensive scientific discussion (market creation) (Igarashi et al., 1995; Olson et al., 2000; Van Meer et al., 2012, 2013). The scientific debates and actions of animal welfare organizations led to increased public awareness and resistance to animal experimentation (market creation). As a consequence, animal experimentation was put on political agendas and Directive 86/609/EEC and ETS 123 aiming to protect laboratory animals, to discourage animal testing, to facilitate the development of innovative methods and to force the use of innovative methods were implemented in Europe in 1986 (guidance of the search) (European Economic Community, 1986; Council of Europe, 1986; Balls, 1994; Baumans, 2004; Kolar, 2006, European Commission, 2012a, 2012b). ${ }^{4}$

The reduced public acceptance of the use of animal experimentation created legitimacy to develop innovative methods (counteracting resistance to change). As a result, resources were increasingly invested in the development of animal-free methods to assess the safety, efficacy and quality of medicines, including animal-free methods for EPO potency testing (resource mobilization).

At the end of the 1970s the amino acid sequence of EPO was identified and the corresponding gene isolated. Based on that gene the biotech company Amgen developed the medicine EPO. EPO entered the market in the 1990s. Under influence of the institutional logic of medicine development, quality control for EPO had to be formalized. EPO potency testing is a component of the quality control of EPO. Potency is the ability of medicines to exert their intended activity (Mire-Sluis, 2001). EPO potency is dependent on correct folding for binding affinity and signal transduction and on glycosylation to decelerate clearing from the body by the liver (Imai et al., 1990; Watson and Yao, 1993; Barth et al., 2007; Ferretto et al., 2009).

EPO potency testing is required because every produced batch of EPO has a different composition. EPO is produced in cells. The folding and glycosylation of EPO are not fully controlled processes because they are dependent on the conditions in the cell. Slightly different process conditions or starting materials can result in other end-products. This means that the folding and the glycosylation patterns can vary within and between batches. To safeguard acceptable and comparable dosing regimens for patients the potency of all EPO batches needs to be assessed.

The practice to assess the potency of this new medicine still needed to be developed. Before EPO received market approval in the 1990s, several studies had already been done to develop animal-free methods to assess EPO potency (entrepreneurial activity). It had taken decades of research to correlate the potency of protein medicines in animals with the results of animal-free methods (knowledge development), and the development of animal-free methods for EPO potency testing showed additional difficulties (Barth et al., 2007). The potency of most protein medicines depends only on binding affinity and signal transduction, whereas for EPO potency there is also a strong, but not fully understood, correlation between glycosylation and potency (Imai et al., 1990; Watson and Yao, 1993; Barth et al., 2007; Ferretto et al., 2009, Industry1, 2011). Various animal-free methods to assess EPO potency, such as quantitative Western method, radioimmunoassay (RIA), capillary zone electrophoresis (CZE) and iso-electric focusing (IEF), were developed (knowledge development, knowledge diffusion and entrepreneurial activity) (Hammerling et al., 1996; Goldwasser et al., 1975; Sherwood and Goldwasser, 1979, Watson and Yao, 1993, Bietlot and Girard, 1997). These innovative methods were developed in research laboratories, by manufacturers and at universities. These projects were often funded internally or with public money (resource mobilization) (Researcher1, 2011; Researcher2, 2011; Researcher3, 2011). Nevertheless, it remained a scientific challenge to assess glycosylation, being another factor influencing EPO potency.

\footnotetext{
${ }^{4}$ Directive 86/609/EEC was revised in 2010 to further foster the development of animal-free methods (European Commission, 2012a).
} 


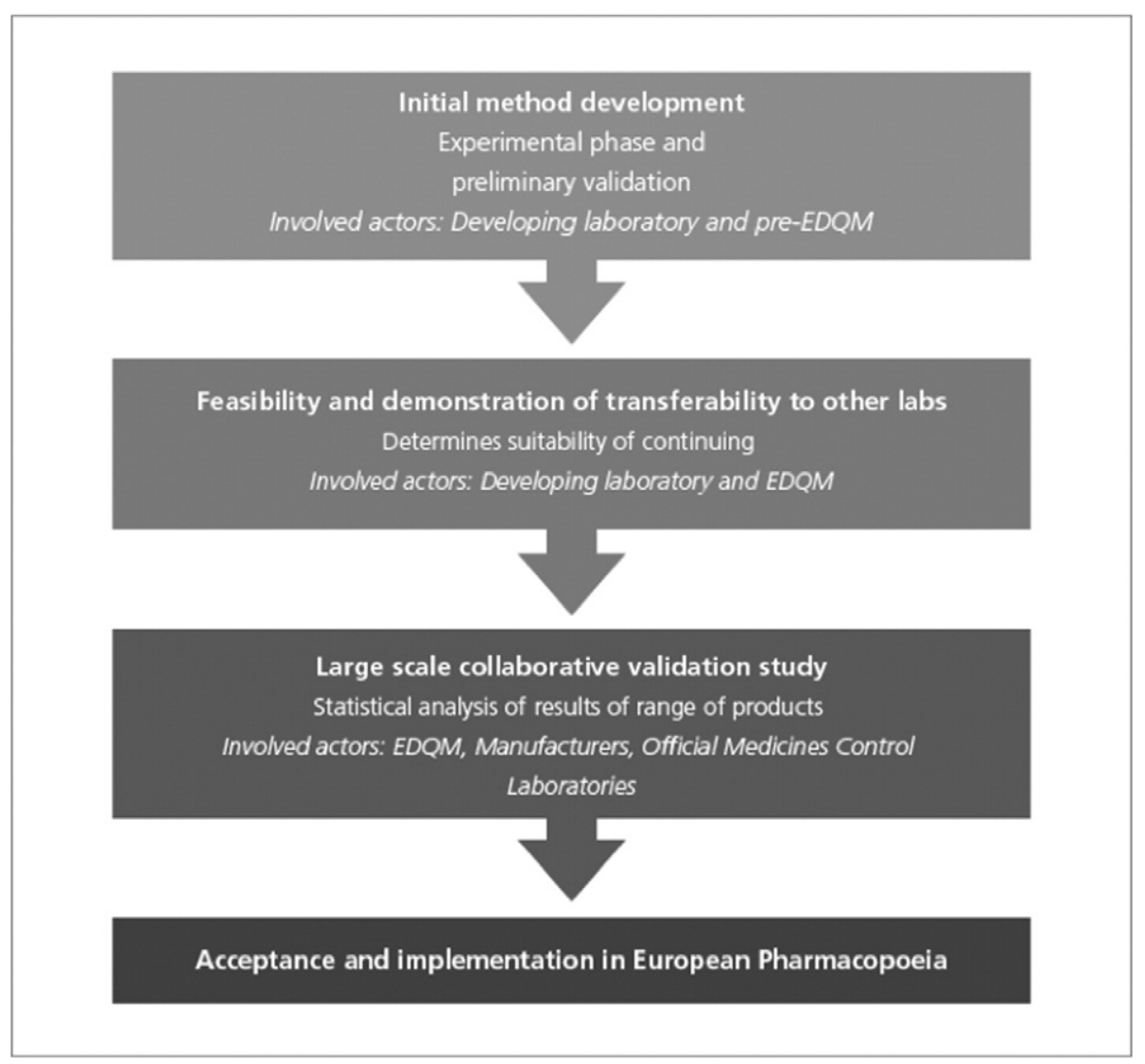

Fig. 1. Basic summary of validation procedure (based on Coune, 2007).

The public resistance to the use of animal studies counteracted resistance to change. This resulted in guidance of the search and resource mobilization to reduce animal studies in the European Union. Hereby, a market was created for innovative methods to replace animal studies. The development of methods to assess the potency of EPO was influenced by this societal change. The legitimacy to develop innovative methods and availability of resources stimulated knowledge development, knowledge diffusion and entrepreneurial activities with innovative methods to assess EPO potency. A technological innovation system (TIS) of animal-free EPO potency testing emerged.

\subsection{Institutionalization of the EPO potency testing practice}

Following the institutional logic of medicine development, the EDQM formulated a draft monograph for EPO quality control in 1996 (regulative element). The actors involved in the TIS of animal-free EPO potency testing had been very successful in developing (knowledge development) and experimenting with (entrepreneurial activity) animalfree methods to assess folding and binding affinity. However, the TIS actors did not manage to develop a method to quantitatively measure glycosylation (Regulator1, 2011). Without being able to measure and quantify glycosylation it is not possible to predict the potency of EPO using animal-free methods (Garthoff et al., 1995; Bristow and Charton, 1999).

Therefore, the EDQM proposed to implement two animal tests ${ }^{5}$ in which the potency is mapped by directly measuring the increase in

\footnotetext{
${ }^{5}$ Method 1: The activity of the preparation in estimated by examining under given conditions, its effect in stimulating the incorporation of ${ }^{59} \mathrm{Fe}$ into circulating red blood cells of mice made polycythaemic by exposure to reduced atmospheric pressure. Method 2: The assay based on the measurement of stimulation of reticulocyte production in normocythaemic mice.
}

red blood cells in mice after injecting EPO in 1996 (EDQM, 1996). To determine comparable dosage the increase in red blood cells is related to the increase of red blood cell induced by the reference product ( (Biological Reference Preparation $\left.(B R P)^{6}\right)$. The relative potency measured in the animal test as measure for EPO potency in human was never extensively validated. The test was assumed to predict EPO potency in humans (cultural-cognitive element), even though it was recognized that the results of animal tests were variable between animals and between experiments. In 1999 monograph 1316 was implemented in the European Pharmacopoeia, requiring that EPO potency had to be assessed, using one of the two prescribed animal tests, prior to product release (regulative element) (EDQM, 2012).

Influenced by the logic of medicine development, the quality control of EPO had to be formalized soon after market introduction of the new medicine (regulative element). At that time there was no animal-free method available that was able to assess EPO potency and therefore the golden standard of animal experiments in medicine development was implemented in the monograph.

\subsection{Deadlocked innovation due to collective inaction}

Only six months after the implementation of monograph 1316 in 1999, it was concluded that a newly developed anima-free method using CZE could quantitatively assess glycosylation (entrepreneurial activity) (Bristow and Charton, 1999). Of the in total eight animal-free methods for EPO potency testing ${ }^{7}$ none could assess binding, signal

\footnotetext{
${ }^{6}$ Biological reference preparations are medicine standards set by the World Health Organization

7 Some methods developed by manufacturers might be missing in this overview, because they are not published and not shared in interviews for strategic reasons (Industry1, 2011; Industry2, 2011).
} 
transduction and glycosylation ( see Table 3). Only a combination of two methods could assess EPO potency. It was anticipated that a cultured cell assay in combination with this new CZE method could replace the EPO potency test in mice (knowledge development, knowledge diffusion) (Charton and Castle, 2001).

With the implementation of EPO potency testing in monograph 1316 the EPO potency testing practice became embedded in the logic of medicine development. Thereby the TIS of animal-free methods became inextricably connected to the institutional logic of medicine development and its mainly constraining elements. Especially regulative elements of the institutional logic of medicine development restricted the market potential (market creation) for animal-free methods, because only results of methods prescribed in the European Pharmacopoeia are accepted by the EDQM.For market formation it became essential to validate animal-free methods (Fig. 1). For validation, extra entrepreneurial activity became required and therefore additional resources needed to be mobilized. The aim of the TIS actors had to shift. Instead of developing just a method to assess EPO potency, a method to replace the animal tests in the European Pharmacopoeia had to be developed (cultural-cognitive element). The rules for the TIS of animalfree methods were changed when EPO potency was embedded in the institutional logic of medicine development. Institutional elements directly influenced the TIS and complicated the innovation process as more activity became required, such asknowledge development (set up of a validation study), knowledge diffusion (transfer of innovative methods to participating laboratories), entrepreneurial activities (carrying outthe validation experiments), resource mobilization (financing the validation process) and counteracting resistance to change (convincing all the member states of the EDQM that the innovative methods can replace the animal tests).

The actors in the TIS considered validation of the animal-free methods a barrier to innovation. The investments to validate innovative methods are high and the chance of success was considered low. Due to the nature of the validation requirements (correlation with the animal study results), the results of validation studies were expected to be disputable making unanimous acceptation by the member states of the EDQM unlikely, and thus implementation in the European Pharmacopoeia, uncertain. Using high correlation with the results of the EPO potency test in mice as a validation requirement is unrealistic. Demonstrating high correlation between the animal test and the combined animal-free method is technically not possible for three reasons. Firstly, it is unclear how to correlate the results of the animal test, directly measuring the effect of EPO on red blood cell production, with the results of a combination of animal-free methods indirectly measuring the potency of EPO (Industry2, 2011; NR L2, 2011; NR L3, 2011). Secondly, the results of the animal test are variable while this is less the case for animal-free methods (EDQM, 2012; Jelkmann, 2009). Finally, experience with the animal tests showed that these tests are not very sensitive (EDQM, 2012; Jelkmann, 2009). An interviewee from industry stated: "The reticulocyte assay (Method $B$ ) is ... a very imprecise assay... it is very difficult to detect a $50 \%$ change of activity... The iron ${ }^{59}$ incorporation assay (Method A) can detect something like a 20-25\% change in activity"
(Industry 2, 2011). Actor apathy hampered the validation process because the risk was regarded high as it remained unclear how to show high correlation between one direct indicator and a combination of indirect indicators, whereof the direct indicator shows variability and has a lower sensitivity.

The uncertainty and additional requirements for the success of animal-free methods for EPO potency reduced the legitimacy for investing in animal-free methods for EPO potency testing. Furthermore, the costly validation process in combination with the norm that patented practices are not accepted in the monographs of the European Pharmacopoeia (Regulator1, 2011) created a free-rider problem as there was no chance of recovering costs of development and validation while other actors could directly profit from these investments if the animal-free methods would be implemented in the monograph.

The EDQM undertook three attempts to lower the barriers that hampered the use of animal-free methods. Firstly, the EDQM attempted to realize collective data gathering by proposing to implement an animal-free method into (regulative) monograph 1316 without replacing the mice test (EDQM, 2002; Regulator1, 2011). The results of the animal-free test provided by manufacturers would be used for the validation. However, the proposed revision was not unanimously accepted by the member states of the EDQM and therefore not adopted (Regulator1, 2011). The main objection was that the description of the animal-free method, the 'in vitro activity assay', was not specified enough (Regulator1, 2011). Secondly, the EDQM attempted to to gather data for validation in collaborative studies for the establishment of EPO BRP batch 2 and 3 in 2004 and 2007 (entrepreneurial activity) (Behr-Gross et al., 2004; Behr-Gross et al., 2007). Thirdly, the EDQM included cultured cell methods and the CZE method into the study design to gather data for the validation of these methods. In both studies only three of the participating laboratories followed upon that request. It was concluded that due to the limited amount of data, the results of the animal-free methods could not be compared with results obtained by animal tests (entrepreneurial activity) (Behr-Gross et al., 2004; Behr-Gross et al., 2007). So, none of the three attempts to foster validation of innovative methods succeeded.

Summarizing, initially there were many promising activities in the TIS of animal-free test methods. The developed technologies had the potential to become the standard to assess EPO potency. Unfortunately, more time then available was needed to develop a set of assays that could assess binding, signal transduction and glycosylation pattern. The logic of medicine development required the formalization of the EPO potency testing practice as EPO received market authorization. Therefore, the only method capable of assessing binding, signal transduction and glycosylation pattern, the variable and limited sensitive EPO potency test in mice, was implemented in the monograph of European Pharmacopoeia. With the implementation in the monograph, the EPO potency testing practice became part of the logic of medicine development and the innovative methods developed in the TIS of animal-free methods became subject to elements of the institutional logic of medicine development. This impacted the rules of the innovation process by introducing a new barrier to the use of animal-free methods.

Table 3

Method characteristics*.

\begin{tabular}{|c|c|c|c|c|}
\hline Method & Binding & Signal transduction & Glycosylation pattern & Accuracy \\
\hline Animal test & + & + & + & Direct \\
\hline Radioimmunoassay (Egrie et al., 1987) & + & - & - & Indirect \\
\hline Cultured cells (Krystal et al., 1981) & + & + & - & Indirect \\
\hline Western method (Hammerling et al., 1996) & + & - & - & Indirect \\
\hline Sialylation-sensitive cell method (Liefooghe et al., 2005) & + & + & \pm & Indirect \\
\hline RP -LC method (Barth et al., 2007) & - & - & + & Indirect \\
\hline MALDI TO F MS method (Llop et al., 2008) & - & - & + & Indirect \\
\hline CZE method (Zhang et al., 2009) & - & - & + & Indirect \\
\hline cIE F method (Cifuentes et al., 1999) & - & - & + & Indirect \\
\hline
\end{tabular}

\footnotetext{
* This list of criteria is not exhaustive and not prioritized.
} 
Animal-free methods now had to be validated according to the institutional elements in order to replace the animal test in the monograph (regulative element). Although only six months after the implementation of the EPO potency test in mice in the monograph, a combined animal-free method to assess EPO potency became available. The additional requirements animal-free methods had to meet deadlocked the innovation process. The validation procedure was never initiated. There were inadequate incentives to initiate the validation studies and the developers of the innovative methods often did not have the resources, that isnot sufficient resource mobilization, to conduct validation studies. In addition, the cost of validation could not be recovered as patented methods are not accepted by the EDQM. So there was not sufficient market creation. A free-rider problem and lack of need to change the gold standard caused a collective action problem.

This study demonstrated that barriers to the use of innovative methods developed in the TIS are lower when there is not yet an established practice in an institutional logic. Once a practice is established, innovative methods need to compete with the established methods. This is especially challenging when it is difficult to compare the performance of practices. This can be the case if, for example, there is a misfit in the unit of analysis of competing practices whereby it is often problematic to correlate results. In this case study, a regulative element (monograph of European Pharmacopoeia) further impeded innovation as it prescribed that it is not allowed to use innovative methods unless they are validated and adopted in the monograph. The required validation exercise will not result in incontrovertible conclusions as it is not possible to correlate the results of a set of innovative methods to the result of the established animal study. This misalignment between innovative methods and the institutional logic structuring drug development need to be resolved to enable innovation.

Conceptually, the study also shows that the development and diffusion of a novel technology can be better explained by combining a TIS analysis with an institutional analysis of existing practices than by a TIS analysis alone. The problems for TIS actors in gaining legitimacy are better understood when analysts also have insight in the prevailing institutions.

\section{Conclusion}

The aim of this article was to increase understanding about the persistence of established practices and its effect on emerging innovations by combining the TIS approach with institutional logics. We studied the EPO potency testing practice in drug development as an exploratory case. By doing that we aimed to contribute to the theoretical understanding of how institutional logics hamper complex innovation processes.

This study showed that the concept of institutional logic is a powerful heuristic to understand the lock-in of established practices in drug development and the effect of this lock-in on the innovation process of innovative methods. Firstly, the analysis of the institutional logic of medicine development provided insight in why the EPO potency test was implemented in regulation in the first place. The combined approached showed that chances for innovative animal-free testing methods and established practices are unequal as acceptance criteria for established practices are lower than for innovative methods. Due to the strong alignment of assumptions, values, beliefs and rules about the use and value of animal studies in drug development, animal studies retain their status as gold standard. Once the established practice is institutionalized, barriers to innovation increase further. This analysis showed that the implementation of established practices in new regulations should be prevented because formalization of established practices hampers the innovation process towards innovative methods.

Secondly, although the emergence of novel technologies is crucial for change, insight in the institutional logic wherein animal studies are embedded helps to understand the origin of several mechanisms that hampered the innovation process. These insights elucidated the mismatch between the institutional logic of drug development and innovative methods to substitute animal studies and thereby provided understanding about why innovative methods could not break through. Replacing the EPO potency test in mice was not realized because the elements of the medicine development logic were well aligned towards animal studies as model for humans. The innovative methods, for example, have to provide similar results as the animal test and this similarity has to be demonstrated in multi-laboratory validation studies.

In the highly regulated drug development field, institutions play a major role in the innovation process, especially regarding the practice of animal testing, the gold standard in the potency and safety assessment of new and established drugs. As we want to understand the role of institutional logic in emerging technological fields, animal testing is an adequate illustrative case study. It delivers a thorough understanding of the power of institutionalization of practices, thereby bridging the innovation and transition literature with notions from institutional sociology and change (e.g. Garud et al. 2007; Lawrence et al., 2009; Maguire et al. 2004; Scott, 2008), in order to create more detailed insights in the institutional context of emerging technological fields.

The theoretical lesson to be learned from this case is that the influence of the institutional logic, which reinforces the established practice, on the emerging innovation process is often undervalued in innovation and transition literature. For radical change processes a better understanding of influencing institutional logics contributes to the understanding of the innovation process as it provides insight in the origin of barriers and helps to identify potential future barriers to innovation induces by the established institutional logic. This analysis provides leads to resolve barriers and anticipates to potential barriers of the future.

Based on our findings it can be concluded that the combined analysis of the functions of the TIS of innovative methods and the institutional logic structuring drug development enriched our understanding of the studied innovation process. The studied case may present and extreme case due to the highly regulated character of drug development, the specific perception of risks related to drugs, and a lack of normal market conditions. Yet, all emerging technologies compete in one way or another with established practices and the institutional logic wherein they are embedded. The mechanisms by which the institutional logic hampered innovation in this case may also explain slow innovation processes in other fields, such as the slow adoption of electric vehicles or solar panels and shed a different light on the emergence and success of new technological fields.

\section{Acknowledgement}

We would like to thank the interviewees for their cooperation. This research was conducted under the framework of Top Institute Pharma, (project T6-301).

\section{References}

Balls, M., 1994. Replacement of animal procedures: alternatives in research, education and testing. Lab. Anim. 28 (3), 193

Barth, T., Sangoi, M.D.S., Silva, L.M.D., Ferretto, R.M., Dalmora, S.L., 2007. Assessment of rhEPO in pharmaceutical formulations by a reversed-phase liquid chromatography method and bioassay. J. Liq. Chromatogr. Relat. Technol. 30 (9-10), 1277-1288.

Baumans, V., 2004. Use of animals in experimental research: an ethical dilemma? Gene Ther. 11 (Suppl. 1), S64-S66.

Behr-Gross, M.E., Daas, A., Bristow, A.F., 2004. Collaborative study for the establishment of erythropoietin BRP batch 2. Pharmeuropa Bio 2004 (1), 23-33.

Behr-Gross, M.E., Daas, A., Burns, C., Bristow, A.F., 2007. Collaborative study for the establishment of erythropoietin BRP batch 3. Pharmeuropa Bio 2007 (1), 49-66.

Bergek, A., Jacobsson, S., Carlsson, B., Lindmark, S., Rickne, A., 2008. Analyzing the functional dynamics of technological innovation systems: a scheme of analysis. Res. Policy 37 (3), 407-429.

Bergek, A., Hekkert, M., Jacobsson, S., Markard, J., Sandén, B., Truffer, B., 2015. Technological innovation systems in contexts: conceptualizing contextual structures and interaction dynamics. Environ. Innov. Soc. Trans. 16, 51-64.

Berman, E.P., 2012. Explaining the move toward the market in US academic science: how institutional logics can change without institutional entrepreneurs. Theory Soc. 41 (3), 261-299. 
Bietlot, H.P., Girard, M., 1997. Analysis of recombinant human erythropoietin in drug formulations by high-performance capillary electrophoresis. J. Chromatogr. A 759 (1-2), 177-184.

Bristow, A.F., Charton, E., 1999. Assessment of the suitability of a capillary zone electrophoresis method for determining isoform distribution of erythropoietin. Pharmeuropa 11 (2), 290-300.

Caronna, C.A., 2004. The misalignment of institutional "pillars": consequences for the U.S health care field. J. Health Soc. Behav. 45 (Suppl(2004)), 45-58.

Charton, E., Castle, P., 2001. Reduction, replacement and refinement of animal tests in the European Pharmacopoeia: recent developments for monographs on biological substances and preparations. Pharmeuropa 13 (1), 94-96.

Cifuentes, A., Moreno-Arribas, M.V., De Frutos, M., Díez-Masa, J.C., 1999. Capillary isoelectric focusing of erythropoietin glycoforms and its comparison with flat-bed isoelectric focusing and capillary zone electrophoresis. J. Chromatogr. A 830 (2), 453-463.

Council of Europe, 1986. ETS 123-European Convention for the Protection of Vertebrate Animals used for Experimental and Other Scientific Purposes.

Coune, C., 2007. Presentation at IP A-EDQM-IDMA Convention: Monograph Development Process for the European Pharmacopoeia: How to Participate in the Work Programme of the European Pharmacopoeia. Retrieved December 13, 2012, from. http:// www.ipapharma.org/events/speakerpresentation.html.

Dosi, G., 1982. Technological paradigms and technological trajectories. Res. Policy 11, $147-162$.

EDQM, 1996. Draft monograph 1316-erythropoietin concentrated solution. Pharmeuropa 8 (3).

EDQM, 2002. Proposal for revision monograph 1316 erythropoietin concentrated solution. Pharmeuropa 14 (1)

EDQM, 2012. European Pharmacopoeia 7.5. EDQM. (n.d.). Vision Mission Values (Retrieved December 13, 2012, from http://www.edqm.eu/en/EDQM-mission-values604.html).

EDQM1. (n.d.). European Pharmacopoeia -Background \& Legal Framework. Retrieved December 13, 2012, from http://www.edqm.eu/en/background-50.html.

Egrie, J.C., Cotes, P.M., Lane, J., Das, R.E.G., Tam, R.C., 1987. Development of radioimmunoassays for human erythropoietin using recombinant erythropoietin as tracer and immunogen. J. Immunol. Methods 99 (2), 235-241.

Elzen, B., Geels, F.W., Leeuwis, C., Van Mierlo, B., 2011. Normative contestation in transitions "in the making": animal welfare concerns and system innovation in pig husbandry. Res. Policy 40 (2), 263-275.

European Commission, 2012a. Laboratory Animals. Retrieved December 13, 2012, from. http://ec.europa.eu/environment/chemicals/lab_animals/home_en.htm.

European Commission, 2012b. Legislation for the protection of animals used for scientific purposes. Retrieved December 13, 2012, from. http://ec.europa.eu/environment/ chemicals/lab_animals/legislation_en.htm.

European Commission Directive 2001/83/ EC, 2001. Retrieved from. http://eurlex.europa. eu/LexUriServ/LexUriServ.do?uri=OJ:L:2001:311:0067:0128:en:PDF.

European Economic Community, 1986. Council Directive 86/609/EEC of 24 November 1986 on the approximation of laws, regulations and administrative provisions of the Member States regarding the protection of animals used for experimental and other scientific purposes. Retrieved from. http://eur-lex.europa.eu/LexUriServ/ LexUriServ.do?uri=CELEX:31986L0609:EN:NOT.

Ferretto, R.M., Leal, D.P., Da Silva, L.M., Nogueira, D.R., Dalmora, S.L., 2009. Validation of a size-exclusion LC method and assessment of rhepo in pharmaceutical formulations by liquid chromatography and biological assay. J. Liq. Chromatogr. Relat. Technol. 32 (10), 1392-1406.

Friedland, R., Alford, R.R., 1991. Bringing society back in: symbols, practices, and institutional contradiction. In: Powell, W.W., DiMaggio, P.J. (Eds.), The New Institutionalism in Organizational Analysis, pp. 232-263 First.

Fuenfschilling, L. Truffer, B., 2014. The structuration of socio-technical regimes-conceptual foundations from institutional theory. Res. Policy 43, 772-791.

Garthoff, B., et al., 1995. Safety and efficacy testing of hormones and related products. ATLA 23, 699-712

Garud, R., Hardy, C., Maguire, S., 2007. Institutional entrepreneurship as embedded agency: An introduction to the special issue. Organ. Stud. 28 (7), 957-969.

Geels, F., 2002. Technological transitions as evolutionary reconfiguration processes: a multilevel perspective and a case-study. Res. Policy 31 (8-9), 1257-1274

Geels, F.W., 2005. The dynamics of transitions in socio-technical systems: a multi-level analysis of the transition pathway from horsedrawn carriages to automobiles (1860-1950). Tech. Anal. Strat. Manag. 17 (4), 445-476.

Goldwasser, E., Eliason, J.F., Sikkema, D., 1975. An assay for erythropoietin in vitro at the milliunit level. Endocrinology 97 (2), 315-323.

Greenwood, R., Suddaby, R., 2006. Institutional entrepreneurship in mature fields: the big five accounting firms. Acad. Manag. J. 49 (1), 27-48.

Hammerling, U., Kroon, R., Wilhelmsen, T., Sjödin, L., 1996. In vitro bioassay for human erythropoietin based on proliferative stimulation of an erythroid cell line and analysis of carbohydrate-dependent microheterogeneity. J. Pharm. Biomed. Anal. 14 (11), 1455-1469.

Hardy, C., Maguire, S., 2008. Institutional Entrepreneurship. In: Greenwood, R. (Ed.), Sage Handbook of Organizational Institutionalism. Sage Publications Ltd., pp. 198-217 First.

Heckathorn, D.D., 1996. The dynamics and dilemmas of collective action. Am. Sociol. Rev. 61 (2), 250-277.

Hekkert, M.P., Negro, S.O., 2009. Functions of innovation systems as a framework to understand sustainable technological change: empirical evidence for earlier claims. Technol. Forecast. Soc. Chang. 76 (4), 584-594.

Hekkert, M.P., Suurs, R.A.A., Negro, S.O., Kuhlmann, S., Smits, R.E.H.M., 2007. Functions of innovation systems: a new approach for analysing technological change. Technol. Forecast. Soc. Chang. 74 (4), 413-432.
Hoffman, A.J., 1999. Institutional evolution and change: environmentalism and the U.S chemical industry. Acad. Manag. J. 42 (4), 351-371.

Igarashi, T.I., Nakane, S., Kitagawa, T., 1995. Predictability of clinical adverse reactions of drugs by general pharmacology studies. J. Toxicol. Sci. 20 (2), 77-92.

Imai, N., Higuchi, M., Kawamura, A., et al., 1990. Physicochemical and biological characterization of asialoerythropoietin. Suppressive effects of sialic acid in the expression of biological activity of human erythropoietin in vitro. Eur. J. Biochem. 194 (2), 457-462.

Industry1, 2011. Interview with representative from pharmaceutical industry 09/08 2011.

Industry2, 2011. Interview with representative from pharmaceutical industry 20/09/ 2011.

Jacobsson, S., Bergek, A., 2011. Innovation system analyses and sustainability transitions: contributions and suggestions for research. Environ. Innov. Soc. Trans. 1 (1), 41-57.

Jelkmann, W., 2009. Efficacy of recombinant erythropoietins: is there unity of international units. Nephrol. Dial. Transplant. 24 (5), 1366-1368.

Kalantaridis, C., Fletcher, D., 2012. Entrepreneurship and institutional change: a research agenda. Entrep. Reg. Dev. 24 (3-4), 199-214.

Kemp, R., Schot, J., Hoogma, R., 1998. Regime shifts to sustainability through processes of niche formation: the approach of strategic niche management. Tech. Anal. Strat. Manag. 10 (2), 175-198.

Kolar, R., 2006. Animal experimentation. Sci. Eng. Ethics 12 (1), 111-122.

Krystal, G., Eaves, A.C., Eaves, C.J., 1981. A quantitative bioassay for erythropoietin, using mouse bone marrow. J. Lab. Clin. Med. 97 (2), 144-157.

Lawrence, T.B., Suddaby, R., 2006. Institutions and institutional work. In: Clegg, S.R. Hardy, C., Lawrence, T., Nord, W.R. (Eds.), The SAGE Handbook of Organization Studies. SAGE, pp. 215-254 Second.

Lawrence, T.B., Suddaby, R., Leca, B., 2009. Introduction: Theorizing and studying institutional work. Institutional Work: Actors and Agency in Institutional Studies of Organizations 1-28.

Liefooghe, E.C., Tiplady, R., Gerson, P., Lloyd, P., Heath, A., Bristow, A.F., 2005. A sialylationsensitive cell-based in vitro bioassay for erythropoietin; incorporation of the galactosebinding Erythrina crista-galli lectin. Biologicals 33 (3), 161-167.

Llop, E., Gutiérrez-Gallego, R., Segura, J., Mallorquí, J., Pascual, J.A., 2008. Structural analysis of the glycosylation of gene-activated erythropoietin (epoetin delta, Dynepo). Anal. Biochem. 383 (2), 243-254.

Maguire, S., Hardy, C., 2009. Discourse and deinstitutionalization: the decline of DDT. Acad. Manag. J. 52 (1), 148-178.

Maguire, S., Hardy, C., Lawrence, T.B., 2004. Institutional Entrepreneurship in Emerging Fields: HIV / AIDS treatment Advocacy in Canada. Acad. Manag. J. 47 (5), 657-679.

Markard, J., Truffer, B., 2008. Technological innovation systems and the multi-level perspective: towards an integrated framework. Res. Policy 37 (4), 596-615.

Markard, J., Raven, R., Truffer, B., 2012. Sustainability transitions: an emerging field of research and its prospects. Res. Policy 41 (6), 955-967.

Mire-Sluis, A.R., 2001. Progress in the use of biological assays during the development of biotechnology products. Pharm. Res. 18 (9), 1239-1246.

Monamy, V., 2000. Animal Experimentation. Cambridge University Press, Cambridge, p. 110.

Negro, S.O., Hekkert, M.P., Smits, R.E., 2007. Explaining the failure of the Dutch innovation system for biomass digestion-a functional analysis. Energ. Policy 35 (2), 925-938.

Negro, S.O., Suurs, R.A.A., Hekkert, M.P., 2008. The bumpy road of biomass gasification in the Netherlands: explaining the rise and fall of an emerging innovation system. Technol. Forecast. Soc. Chang. 75 (1), 57-77.

NR L1, 2011. Interview with representative of National Research Laboratory 07/01/2011.

NR L3, 2011. Interview with representative from national research laboratory $13 / 07$ 2011.

NR L2, 2011. Interview with representative from national research laboratory 21/06/2011.

Oliver, P.E., 1993. Formal models of collective action. Annu. Rev Sociol 19 (1), 271-300.

Olson, H., Betton, G., Robinson, D., Thomas, K., Monro, A., Kolaja, G., Lilly, P., et al., 2000. Concordance of the toxicity of pharmaceuticals in humans and in animals. Regul. Toxicol. Pharmacol. 32 (1), 56-67.

Rägo, L., Santoso, B., 2008. Drug regulation: history, present and future. In: van Boxtel, C.J. Santoso, B., Edwards, I.R. (Eds.), Drug Benefits and Risks: International Textbook of Clinical Pharmacology Vol. 2. IOS Press, pp. 65-77.

Rao, H., Monin, P., Durand, R., 2012. Institutional change in Toque Ville: nouvelle cuisine as an identity movement in French. Am. J. Sociol. 108 (4), 795-843.

Reay, T., Hinings, C.R., 2009. Managing the rivalry of competing institutional logics. Organ. Stud. 30 (6), 629-652.

Regulator1, 2011. Interview with representative from legislative body 29/07/2011.

Researcher1, 2011. Interview with researcher at university research group 18/01/2011.

Researcher2, 2011. Interview with researcher at university research group 02/02/2011.

Regulator3, 2011. Interview with researcher at university research group 30/11/2011.

Ryder, R.D., 2000. Animal Revolution: Changing Attitudes Towards Speciesism. Berg Publishers.

Scott, W.R., 2001. Institutions and Organizations. (Second.). Sage Publications Inc., United States.

Scott, W.R., 2008. Institutions and Organizations-Ideas and Interest. Third. Sage Publications Inc., United States, pp. 1-266.

Seo, M.-G., Creed, W.E.D., 2002. Institutional contradictions, praxis and institutional change: a dialectical perspective. Acad. Manag. Rev. 27 (2), 222-247.

Sharif, N., 2006. Emergence and development of the National Innovation Systems concept. Res. Policy 35 (5):745-766. http://dx.doi.org/10.1016/j.respol.2006.04.001.

Sherwood, J.B., Goldwasser, E., 1979. A radioimmunoassay for erythropoietin. Blood 54 (4), 885.

Suurs, R.A.A., Hekkert, M.P., 2009. Cumulative causation in the formation of a technological innovation system: the case of biofuels in the Netherlands. Technol. Forecast. Soc. Chang. 76 (8), 1003-1020. 
Thornton, P.H., Ocasio, W., 2005. Institutional Logics. In: Greenwood, R., Oliver, C., Sahlin, K., Suddaby, R. (Eds.), The Sage Handbook of Organizational Institutionalism. Sage, pp. 99-129.

Thornton, P.H., Ocasio, W., 2008. Institutional logics. In: Greenwood, R. (Ed.), Sage Handbook of Organizational Institutionalism. Sage Publications Ltd., pp. 99-129 Firzt.

Thornton, P.H., Ocasio, W., Lounsbury, M., 2012. The Institutional Logics Perspective-A New Approach to Culture, Structure and Process. First. Oxford University Press, pp. $1-234$.

Turnheim, B., Geels, F.W., 2012. Regime destabilisation as the flipside of energy transitions: lessons from the history of the British coal industry (1913-1997). Energ. Policy $50,35-49$.

Unruh, G.C., 2000. Understanding Carbon Lock-in. Energ. Policy 28, 817-830.

Van Alphen, K., Noothout, P.M., Hekkert, M.P., Turkenburg, W.C., 2010. Evaluating the development of carbon capture and storage technologies in the United States. Renew. Sust. Energ. Rev. 14 (3), 971-986.

Van den Bergh, J.C.J.M., Truffer, B., Kallis, G., 2011. Environmental innovation and societa transitions: introduction and overview. Environ. Innov. Soc. Trans. 1 (1), 1-23.

Van Meer, P.J.K., Kooijman, M., Gispen-de Wied, C.C., Moors, E.H.M., Schellekens, H., 2012 The ability of animal studies to detect serious post marketing adverse events is limited. Regul. Toxicol. Pharmacol. 64 (3), 345-349.

Van Meer, P.J.K. van, Kooijman, M., van der Laan, J.W., Moors, E.H.M., Schellekens, H. 2013. The value of non-human primates in the development of monoclonal antibodies. Nat. Biotechnol. 31 (10), 881-882.

Watson, E., Yao, F., 1993. Capillary electrophoretic separation of human recombinant erythropoietin (r-HuEPO) glycoforms. Anal. Biochem. 210 (2), 389-393.

Weber, K., Thomas, L.G., Rao, H., 2009. From streets to suites: how the anti-biotech movement affected german pharmaceutical firms. Am. Sociol. Rev. 74 (1), 106-127.

Wijen, F., Ansari, S., 2007. Overcoming inaction through collective institutional entrepreneurship: insights from regime theory. Organ. Stud. 28 (7), 1079-1100.

Yin, R.K., 2003. Case Study Research: Design \& Methods. third ed. Sage, Thousand Oaks.
Yuan, J., Xu, Y., Hu, Z., 2012. Delivering power system transition in China. Energ. Policy 50, $751-772$.

Zhang, J., Chakraborty, U., Villalobos, A.P., Brown, J.M., Foley, J.P., 2009. Optimization and qualification of capillary zone electrophoresis method for glycoprotein isoform distribution of erythropoietin for quality control laboratory. J. Pharm. Biomed. Anal. 50 (3), 538-543.

Marlous Kooijman PhD is a researcher at Innovation Studies, Copernicus Institute, Utrecht University. Her PhD focused on the use of animal studies in drug development from an innovation perspective.

Marko P. Hekkert is a full professor of Dynamics of Innovation Systems and head of Innovation Studies, Copernicus Institute, Utrecht University.

Peter J. K. van Meer PhD is a researcher at the Utrecht Institute for Pharmaceutical Sciences. As a continuation of his $\mathrm{PhD}$ research his is studying the predictive value of animal studies in drug development

Ellen H. M. Moors is a full professor of Sustainable Innovation. Her research in the field of innovation studies focuses on the dynamics and governance of emerging technologies in science-based sectors, such as agro-food, life sciences and health \& ageing.

Huub Schellekens is a full professor of Innovation in Medical Biotechnology. His research focuses on the relation between structure and function of therapeutic proteins and immunogenicity of biosimilars. He has special interest in sustainable drug development including the cost effectiveness of drug regulation and the predictive value of animal studies. 